(02015, Elsevier. Licensed under the Creative Commons Attribution-NonCommercial-NoDerivatives 4.0 International http://creativecommons.org/about/downloads 


\title{
Instructor $\underline{A}$ pproaches to $\underline{B}$ lended-management $\underline{\text { Learning: A }}$ Tale of Two Business Schools
}

$\underline{\text { Vladlena }}$ Benson $^{\mathrm{a} * *}$ v.benson@kingston.ac.uk Ailsa Kolsaker ${ }^{\mathrm{b}}$

${ }^{a}$ Faculty of Business and Law, Kingston University, Kingston Hill Campus, Kingston Upon

Thames, KT2 7LB London, United Kingdom

${ }^{\mathrm{b} S u r r e y ~ B u s i n e s s ~ S c h o o l, ~ U n i v e r s i t y ~ o f ~ S u r r e y, ~ G u i l d f o r d ~ G U 2 ~ 7 X H, ~ U n i t e d ~ K i n g d o m ~}$

Corresponding author.

\begin{abstract}
The body of academic research on technology-supported learning is growing rapidly, with much of the focus upon student learning effectiveness. This paper addresses the gap in educational technology literature on the examination of instructor characteristics. We shift the focus from student outcomes to instructor input, pedagogy and their strategy of technology selection. In particular, we explore instructors' approaches to blended learning, pedagogical aims and instructional design. Our study of management academics at two UK business schools reveals that blended learning adoption varies greatly. Based on forty semi-structured interviews with management academics, we find that this adoption depends on personal predispositions of academics towards educational technology. Personal understanding and interpretations of the blended learning phenomenon cluster into four distinct groups: traditionalist, pedagogy-centric, techno-centric and cautious, and instructional design and delivery preferences vary widely between groups. The findings of this study demonstrate that there is a wide variation in instructor approaches to blended management learning and that manifests itself markedly in the pedagogical strategies and instructional design and delivery of management education.
\end{abstract}

Keywords: Blended learning; Instructional design; Perceptions of blended learning;

Delivery methods; Management education

\section{Introduction}

Research into technology supported learning, both in its etLearning and blended learning forms, in management education has proliferated over recent years. There have been dramatic conceptual, methodological and analytical advances in the field (Arbaugh, Desai, Rau, \& Sridhar, 2010; Jones \& Kerr, 2012.). Much is now known about the strategic imperatives and resource requirements of learning technology and there have been various attempts to define and measure 'success' and 'effectiveness', mostly framed in terms of 
quantitative metrics of student performance (Jones, Moeeni, \& Ruby, 2005; Klein, Noe, \& Wang, 2006; Kleinman \& Entin, 2002). The research focus has gradually shifted away from pedagogy to strategy and practice.

Technology supported learning takes various forms. Pure online modes (such as pure distance learning programmes), exploit the web for content delivery; there is no expectation of synchronous interaction with faculty; and learners are broadly self-motivated and selfregulating (Jones et al., 2005; Tsai, 2010). Blended learning entails a combination of off- and online methods and is the predominant mode of contemporary technology supported learning (Baugher, Varanelli, \& Weisbord, 2003; Bonk \& Graham, 2006). Firmly embedded as a cornerstone of teaching and learning strategy, it 'combines instructional delivery in a traditional face-to-face context with online learning, either synchronously or asynchronously' (Gribbens, Hadidi, Urbaczewski, \& Vician, 2007, p. 741). In blended learning, faculty devise teaching and learning strategies that purposively include both traditional face-to-face encounters (in lectures, seminars, tutorials and supervisory sessions) with virtual modes of delivery, the latter including both asynchronous content delivery such as slides, cases, seminar notes; podcasts, blogs, videos, mash-ups, synchronous discussions, and a simultaneous mix of synchronous face-to-face and online instruction (Turner, 2015). In this paper we argue that the literature on blended learning often focuses on fragmented applications of technology in classroom (e.g. (Jones \& Kerr, 2012)) and the pedagogical value of blended learning may be lost owing to the enthusiasm about technology, and mistaking the novelty of technology for its pedagogical value. Studies on blended learning provide examples of blended learning evaluations and how it stands up to scrutiny of its efficiency. For example, Bentley, Selassie, and Parkin (2012) present evaluation of a blended learning MBA programme. Their conclusions centre on the importance of the instructors' role in the design, delivery, communication and their technological aptitude in blended courses. The roles of students and instructors in various delivery modes have been explored at length (Brady, 2013), the role of the instructor in blended courses and their differences in personal approaches to technology adoption are not-understood fully. Following the gaps identified in (Berger \& Tapol, 2007;Williams \& Williams, 2010), we refocus the research lens by examining the pedagogical benefits of blended learning from the perspective of faculty who use it. We seek to contribute to the literature in two key areas. Firstly, to provide insights into instructors' views of blended learning: 
Research Objective 1: Identify faculty approaches to and views of blended learning - there is a gap in the literature concerning the extent to which instructors embrace blended learning.

Secondly, to examine instructors' pedagogical aims in exploiting blended learning as part of their teaching and learning strategy:

Research Objective 2: Explore pedagogical aims and instructional design-e. Extant research is generally more concerned with blended learning as institutional strategy and, in our view, differentiates inadequately pure online and blended environments. We examine the strategic use of blended learning as a means of achieving pedagogical aims, focusing specifically on teaching approaches and chosen tools; to date research in this area has focused upon student participation behaviours.

We believe that in addressing these specific gaps in the literature this article makes a significant contribution to current understanding of the use of blended learning in management education.

\section{Technology and blended learning}

Technology has become an accepted component of higher education; few universities today have no online provision. Underpinning the widespread embrace of learning technology is acceptance of a largely instrumental, utilitarian approach to education in which learners take greater responsibility for outcomes and a key measure of effectiveness is the extent to which graduates are prepared for the new information age (Alavi \& Gallup, 2003). Stecyk and Chojnowski (2010) report that both learners and instructors rate the efficiency and quality of blended learning twice as high as traditional methods. For Zabriskie and McNabb (2007), a key driver of etlearning in universities is the increasing cost of delivering instructional content through traditional means in the face of high student demand, declining resources and shortages of qualified instructional staff. ELlearning offers the prospect of lower operating costs and economics of scale through standardised content and delivery methods (Salisbury, Pearson, Miller ${ }_{2},-$ \& Marett, 2002) and a shift of emphasis from teaching to learning. In Alavi and Gallup (2003) analysis, strategic and financial imperatives are driving the uptake of technology supported learning modalities; consistent with prevalent economic and social discourses in which education must prove its worth by demonstrating economic as well as intrinsic value. As Lehtinen, Hakkarainen, LipponenRahikainen, and Muukkonen, (1999) observe, one of the basic requirements for education is to prepare 
learners for participation in a networked, information society in which knowledge will be the most critical resource for social and economic development.

For Hwang and Arbaugh (2006), extant studies do little to illuminate the nature and characteristics of effective interaction; it is this general lack of scrutiny of etlearning initiatives, universities- embrace as a strategic necessity, coupled with inadequate delineation of pure online and blended learning within the learning technology research field that leads us to query the overwhelmingly positive findings of extant research. We propose that the primary concern of this emergent field should not be framed dichotomously in terms of online/offline nor overly focused on quantitative effectiveness metrics, but rather how technology is exploited in blended learning contexts to underpin the pedagogical objectives of management education and how it might be further exploited to reinforce pedagogical outcomes in the future. Serwatka (1999) and Tsichritzis (1999) were careful to suggest that the emphasis should be upon the 'transformation' rather than automation of teaching and learning; this transformational approach is supported by Garrison and Kanuka (2004), Graham (2007) and is voiced by Williams and Williams (2010). For Osguthorpe and Graham (2003) the blended environment allows educators to refocus from unilateral delivery to improving student learning, for example, by providing information in advance, hands-on, real-time experiments or posting discussion questions. Many blended learning management programmes are taught primarily through Harvard Business School-style cases studies, and seamlessly yield themselves to online adaptation (for an in-depth review see Rollag (2008)) for which curricula uses 'a mixture of face-to-face and online learning experiences' (Rollag, 2008, p.501). This module design is also advocated by Arbaugh and Benbun-Fitch (2006) who argue that online communication tools, including discussion boards and instant messaging, should occupy a focal point in online instructional design of blended courses instead of being a supplementary or 'bolt-on' activity. The growth of online learning community facilitated by instructors through structured communication is seen by these researchers as the driving force towards improving learning outcomes.

Terry (2007) finds the hybrid model of education, involving a mixture of on-and offline activities, significantly more effective than pure online; for Terry (2007), the blended environment offers flexibility whilst maintaining the high quality and student satisfaction traditionally associated with campus-based courses. Certainly, blended learning modes are highly flexible; the blend varies constantly and is non-prescriptive. Pedagogically, it is no more clear-cut than the pure online model, however; whilst some faculty may employ largely didactic methods, supplemented with some dialogic elements (with the emphasis firmly on 
teaching), others may prefer largely dialogic, action-based learning (which emphasise learning). We support Tsai's (2010) view that educational technologies have not yet succeeded in transforming concepts and practices of teaching and learning, as such, the reality of blended learning remains anchored firmly in traditional approaches to pedagogy.

Rungtusanatham, Ellram, and Siferd (2004) identify three distinct sets of critical issues that educators must address in the use of learning technology: content-related; delivery-related and learning-related, and four models of online delivery: basic overview model; overview with feedback; technical skills; and managerial learning. Adopting the typology by (Rungtusanatham et al., 2004), in this study we focus upon the overview model (with and without feedback) and the managerial learning model within the context of business schools delivering post-graduate management education using blended learning. As the purpose of blended learning in the departments surveyed is not concerned with developing new technological competencies (for example, learning a new programming language, or similar), we do not operationalize the technical skills model in the research that follows.

\section{The instructor role in blended learning}

The growing body of research has not yet produced a consensus on the benefits of online instruction (Clouse \& Evans, 2003), whilst the proliferation of online course provisions means that instructors are, in practice, either already teaching online or increasingly likely to be involved in online delivery in the near future. For Baugher et al. (2003), the level of online instruction may be an indicator of student performance success only if such activity indicates interest, involvement and motivation; here we shift the focus from students to faculty and argue that the instructor plays a pivotal role in the success, or otherwise, of blended learning management education; as such the instructor role merits further investigation. In our view, there is a paucity of literature on the instructor's involvement in blended learning environments; the focus has been overwhelmingly studentoriented, yet (s)he is crucial to the success of blended management education. Salisbury et al. (2002) and Haytko (2001) find that students dislike the lack of inter-personal contact with the instructor inherent in online modes, and Kupczynski et al.'s (2010) recent study of success factors of online courses reveals just how crucial the instructor role is; students rate 'instructional design' and, in particular, 'direct instruction' (in which the instructor essentially tells the learner what to do), extensive, targeted feedback and facilitation of discussions as key components of success. 
We find much of the extant literature to be overly optimistic, skimming some key pedagogical issues of central importance to those tasked with blended learning delivery. For example, Zabriskie and McNabb (2007), following MacDonald and McNabb (2006), state that to be successful, adoption of a new knowledge delivery model must be a reflection of what best meets the needs of all stakeholders. This assumes the possibility of shared, optimal outcomes whilst, in practice, it is conceivable that instructors and learners may have divergent needs, for example, the timing, frequency, availability and duration of 'live chat' sessions. Similarly, for Zabriskie and McNabb (2007) an important component of the delivery-design effort is identification of an instructional design that is fit for purpose; 'right' for students, the university, business school, faculty and subsequent employers. Again, this is intensely challenging; it is not difficult to conceive of design elements that might suit faculty, but not students, business schools or employers_(Benson \& Anderson, 2010; Benson \& Morgan, 2014)

We support the view of Rungtusanatham et al. (2004) that successful blended learning strategy requires clear educational goals, specific and clearly articulated so that an appropriate plan can be devised to address content-related, delivery-related and learningrelated concerns. We support researchers' observation further that faculty have to spend significant amounts of time developing and providing content at potentially high opportunity cost; indeed, Terry, Owens, and Macy (2000) estimate preparation time to be in the region of $400 \mathrm{~h}$ per new course. In practice, therefore, there may not exist amongst faculty the level of interest in and commitment towards technology supported teaching implied in much of the literature.

In terms of learning and teaching styles, recognising that faculty have a role to play in student self-regulated learning_is paramount, for Tsai (2010) students need communication and feedback from instructors to improve their learning. Ideally, blended learning should comprise symbiotic interaction between instructor and learners and, indeed, the blended learning environment provides numerous opportunities for ongoing dialogic exchange between parties, potentially improving pedagogical outcomes. Various studies explore adoption of learning technology in terms of student outcomes (Alavi, Marakas, \& Yoo, 2002; Chen \& Jones, 2007; Clouse \& Evans, 2003; Ice, Curtis, Phillips, \& Wells, 2007; Jones \& Kerr, 2012; Klein et al., 2006; Navarro \& Shoemaker, 2000; Vician \& Brown, 2001). For Bentley et al. (2012) in technology-mediated environments, instructor style and teaching style are key drivers of student participation and engagement, thus for blended learning to be positive for both parties, faculty must actively opt in. For Rungtusanatham et al. (2004), 
institutions must clarify whether faculty are expected to develop and teach online courses as part of their normal teaching load, whilst for Alavi and Gallup (2003), faculty involvement must be voluntary. Furthermore Turner (2015), based on the evaluation of podcasts in management teaching, indicates the importance of the instructor-led shift from a didactic to a resource-based pedagogy. There are several issues that merit consideration, but are often inadequately addressed: in particular, the need for significant investment in technology, training and on-going support for instructors_(Benson \& Anderson, 2010), clarity around workload and intellectual property issues, opportunities to meet and share experiences (Alavi \& Gallup, 2003; Rungtusanatham et al., 2004).

In terms of design choices, Rollag (2008) argues that individual faculty have their personal strategies for teaching online, for example, case-study based learning. Also, for Rollag (2008), the extant literature fails to provide a thorough account of a comprehensive set of design choices and trade-offs associated with designing, facilitating, and assessing an effective and efficient online pedagogical strategy. It is apparent that being equipped with the necessary skills for convening blended learning courses will become increasingly important to many business faculty, yet there is evidence that skills training is not being provided adequately. For Gribbens et al. (2007), to maximize the potential successes for blended learning classrooms, educators and students alike must become comfortable with and trained in the newer technologies. They state, 'Without the training, students will likely not do much more than read-and-regurgitate, missing out on the excitement of continuous learning. Similarly, without the training, educators will likely just do what they have always done, just in a different format. When the training has been offered and completed, blended learning classes make it possible to have a richer environment than a traditional classroom' (Gribbens et al., 2007, p. 745).

A well-trained, motivated instructor is key. Thornton and Yoong (2011) highlight the importance of the instructor in enabling learning and acting as a trusted inquisitor. For Arbaugh and Hwang (2006), drawing upon the Community of Inquiry (CoI) model (Garrison, Anderson, \& Archer, 2000), teaching presence is a crucial element of effective teaching and learning, by which they mean 'the design, facilitation, and direction of cognitive social processes for the purpose of realizing personally meaningful and educationally worthwhile learning outcomes' (2000, p.1). Arbaugh and Hwang (2006) find that three elements of the CoI original model: instructional design; facilitating discourse; and direct instruction are separate, but highly correlated, indicating that the online learning environment is challenging and instructors have to fulfil all three roles of teaching presence well. 'Instructional design' 
entails managing the overall organisation and goals of the course and communicate these overall goals and structural boundaries in a meaningful way to students; 'facilitating discourse' is concerned with facilitating ongoing student interactions to make the learning come alive in the virtual environment; and 'direct instruction' involves being the content expert to meet students' knowledge needs when it becomes difficult for self discovery and mutual exchange of ideas to meet their learning goals. For Arbaugh and Hwang (2006) the ability to establish this presence and help students achieve personally meaningful and educationally worthwhile learning outcomes will depend very much on the instructor addressing all three components of teaching presence at the same time.

It is also important to consider the place of faculty teaching skills in university value systems. Several sources highlight that academics' subject expertise and research output, not teaching skills, primarily secure success in higher education (Amundsen, Weston, \& McAlpine, 2008; Becher \& Trowler, 2001; McMahon, Gardner, Gray, \& Mulhern, 2001). Yet academics spend significant part of their career teaching and supervising projects with, in some cases, relatively basic understanding of the pedagogy underpinning formal learning processes or instructional design rationale. For Clark and James (2004), earlier course delivery experiences as well as textbook content serve as strategies in course design resulting in the academic simply producing a list of topics to be taught. Trade-offs of this approach include academics being overly constrained and perceiving some inconsistency between the materials they are trying to teach and their understanding of that content (Clark \& James, 2004). It could be argued that personal understanding and interpretation of the blended learning phenomenon by faculty plays a crucial role in instructional design choices and even more so in deciding which blended learning tools and strategies to adopt in order to address the complexities of managerial education from the students' perspective.

\section{Method of inquiry}

This study focuses on academics' experiences of blended learning at two UK business schools and seeks to examine the ways in which personal ways of interpreting and understanding blended learning phenomenon influence teaching strategy and methods. It is also of interest to this research to identify how blended learning is used in practice and explore how content design and resources fit with student expectations and requirements. We explore the extent to which faculty embrace blended learning as a teaching and learning strategy in management education, and how they are exploiting blended learning tools in terms of course content, delivery modes and teaching and learning practices. Our approach is 
framed by the dual nature of the blended learning adoption, i.e. the interconnection between technology and pedagogy.

Although there now exists a solid body of knowledge about learning technology use, the literature on blended learning adoption from the instructor's position is relatively lean and student performance centred; we therefore consider blended learning based on the views of the instructors and their acceptance of educational technology. In order to explore faculty's experiences, conceptions and understanding of the meaning of blended learning, responding to Ziegenfuss's (2007) observation of a lack of research concerning how faculty in higher education design and develop the courses they teach, and following others (Åkerlind, 2005; Marton \& Booth, 1997) we employ a qualitative exploratory research approach. Described by Marton and Booth (1997, p.130) as 'working toward an articulation of the interviewee's reflections on experience that is as complete as possible', we identify the differing ways of experiencing the phenomena, potentially resulting in varying practice. The focus of this research is to understand blended learning as a phenomenon amongst faculty delivering management education programmes and the effect of this upon (potentially varying) practice amongst instructors. Semi-structured interviews conducted with a purposive sample of experienced management academics formed the data collection method for this study (Marton \& Booth, 1997).

\subsection{Sample description and data analysis}

Pedagogically active faculty were studied in the business schools of two British universities. The research sites are relatively similar in terms of programmes offered, delivery modes, technological maturity and demographics of academics and students. Both research sites embraced blended learning as a core element of their teaching and learning strategies, and both had a learning management system in support of their blended learning strategy. Both institutions exploit the full range of blended learning technologies and methodologies, with academic faculty having some discretion regarding the exact composition of blended teaching and learning; in other words, faculty are not required to utilise all modes of blended learning in their teaching, although both Schools have a minimum expectation regarding utilisation of the learning management platform in teaching and learning. In both blended learning has been in place for over five years and is embedded in the teaching and learning strategies-The research sites are involved in programme delivery with overseas partners and view technology as an enabler and facilitator of partner programme consistency as well as a means of quality assurance. The study was approved by the research ethics committees at both universities. 
The sample of participants was purposive, being constructed deliberately to include subject matter experts across a range of management disciplines rather than novice lecturers, who had been employed by the respective Business Schools for at least two years. The final sample of participants included 40 business and management academics, including 24 academics at research site A and 16 academics at research site B. All interviewed academics were involved in both teaching and research at the time of data collection. They represented the following disciplines: business management, accounting, marketing, human resources, information management and strategy. All had delivered their subject (module) at least once before and majority were involved in leading courses taught by a team of instructors.

All participants had some experience of employing a blend of offline and online teaching strategies and tools. At both research sites the semi-structured interviews followed the same protocol which began by inviting the interviewees to explain which courses they were teaching, describe their teaching strategies, their expectations of student learning in terms of learning objectives, skills and employability. These were followed by questions about teaching and learning strategy, including teaching methods, innovation in teaching practice, assessment and feedback. Academics were also invited to think about future developments or changes to current practice. They were also asked about their understanding of blended learning, experience of using blended learning, its success or failure in helping students achieve pedagogical outcomes, perceived benefits/limitations to students. Finally, they were asked about the required technological aptitude of anyone teaching using blended learning methods, availability of support staff, and staff development requirements. The open ended nature of the questions allowed for clear indication of interviewees' views of blended learning and the salient issues surrounding its use in the two institutions.

Interviews were digitally recorded and transcribed verbatim, making the transcripts the focus of the analysis. For Åkerlind (2005), in qualitative analysis the importance of attempting to maintain an open mind during the analysis is of prime importance. The set of categories or meanings were not established in advance but 'emerged' through the categorisation process, whilst categories and transcripts were treated as a set in order to maintain focus on the collective experience. Employing a process of hierarchical coding, the transcripts were analysed with a view to identifying phenomena emerging naturally from the data. Following Haig (2005), we consider identification of themes and the coding phase particularly crucial; code validation exercise (Kvale, 1996) was employed between researchers when coding the transcripts using NVivo9. The outcome was a compelling and 
practically applicable set of phenomena that identifies both the key issues and variations in blended learning approaches whilst and the key in management education.

Qualitative research traditionally is concerned with validity of outcomes or the degree to which the research results truly reflect the phenomena under investigation. Pragmatic validity check (Kvale, 1996) of the research findings is seen as useful to their intended users. For qualitative research in higher education specifically the test of validity is in the value and practicality of the research insights into teaching and learning (Entwistle, 1997). We therefore argue that findings of this study are useful to a large number of academics involved or considering embarking on blended learning methods of delivery, who would be encouraged to test the practicality of these results in their specific settings.

\section{Results}

The qualitatively distinct interpretations of blended learning were constituted by different respondents describing their teaching practice and experiences of blended learning in their instruction. In line with the research objectives, they were asked specifically about their view of blended learning; their understanding of the strategic aims and objectives of blended learning; the extent to which they employ blended learning methods in their teaching; and their views of the benefits and limitations of blended learning to students.

\subsection{Research objective 1 - approaches to blended learning}

Our first research objective of investigating academics' approaches to blended learning was addressed by means of thematic content analysis. The following dimensions emerged: pedagogical needs, teaching methods, benefits of blended learning to students, limitations of blended learning to students, benefits of blended learning for instructors, drawbacks of blended learning for instructors, future blended learning plans and personal attitudes. The analysis, in which we looked for strength and frequency of coding references, produced four distinct groups which we have labelled: 'Traditionalist',' Pedagogy-centred', 'Technology-centric' and 'Cautious', as shown in Table 1.

Table 1 Typology of blended learning adopters.

\begin{tabular}{|c|c|c|}
\hline Typology & Description & Characteristics \\
\hline Traditionalists & $\begin{array}{l}\text { Perceive their role as subject } \\
\text { specialists, often less } \\
\text { technology savvy, but view } \\
\text { themselves as the locus of } \\
\text { knowledge transmission. }\end{array}$ & $\begin{array}{l}\text { Face-to-face delivery works well for them. Their view of } \\
\text { technology in the classroom is best summarised as 'don't fix what } \\
\text { isn't broken'. }\end{array}$ \\
\hline $\begin{array}{l}\text { Pedagogy- } \\
\text { centred }\end{array}$ & $\begin{array}{l}\text { Focus on effective learning as } \\
\text { the driver of the choice of } \\
\text { teaching methods, including } \\
\text { those mediated by technology. }\end{array}$ & $\begin{array}{l}\text { See blended learning as a potentially useful means of supporting } \\
\text { their pedagogic strategy. Achievement of teaching and learning } \\
\text { objectives is their primary aim; not particularly concerned about } \\
\text { whether or not technology has a role to play; view technology in }\end{array}$ \\
\hline
\end{tabular}




\begin{tabular}{|c|c|c|}
\hline Typology & Description & Characteristics \\
\hline & & the classroom as a vehicle to effective learning. \\
\hline Technocentric & $\begin{array}{l}\text { Perceive technology as a } \\
\text { driver of learning; always } \\
\text { experimenting with ICT; } \\
\text { unsure whether learning } \\
\text { improves as a result. }\end{array}$ & $\begin{array}{l}\text { Tend to experiment with new teaching methods that specifically } \\
\text { require the use of electronic tools; driven more by personal } \\
\text { interest in new technology than achievement of learning goals. } \\
\text { Often adapt teaching methods to be able to exploit new } \\
\text { technology. Believe students are interested in technology, hence } \\
\text { will learn better with new gadgets/applications. }\end{array}$ \\
\hline Cautious & $\begin{array}{l}\text { Perceive blended learning as } \\
\text { artificially forced, uncongenial } \\
\text { to current teaching practices } \\
\text { and watch others test the } \\
\text { waters of technology. }\end{array}$ & $\begin{array}{l}\text { Wary of technology and its implications for the role of instructor } \\
\text { lin changing delivery modes. Strong belief in face-to-face teaching } \\
\text { methods and direct, classroom-based interaction. Little interest in } \\
\text { new technology, and can hold quite extreme, negative views of the } \\
\text { impact of technology in the classroom. Regard new technology is } \\
\text { often 'not worth the effort'. }\end{array}$ \\
\hline
\end{tabular}

In line with Arbaugh and Benbunan-Fich's (2006) findings, the key driver of teaching and learning strategy and design to emerge from the data was pedagogical needs, idiosyncratic to modules and learning cohorts. The interview data indicated clearly that lecturers' choice of teaching and learning tools were influenced heavily by, on the one hand, the practicalities of class size, module level, student background and so on, and on the other, contemplation of how to optimise student learning outcomes.

Additionally, there was a clear indication that personal attitudes and interest in technology had a significant influence on the repertoire of teaching strategies and tools employed. Individual perceptions of blended learning phenomena emerged through the discussion of advantages and drawbacks of blended learning to both instructors and students. Echoing Osguthorpe and Graham's (2003) findings, instructors in the current study cited the key benefits of blended learning (from the students' perspective) as the potential to cater to a variety of learning styles, enhance information accessibility and availability, provide support for those lacking fluency in the language of instruction, as well as addressing students expectations. A number of clear benefits to instructors also emerged, including enabling instructors to optimise the face to face time, by taking some of the more mundane course administration issues online, as well as enhancement of instructor-student communication, coordination of teaching teams, and the accumulation and reuse of online teaching materials.

In terms of drawbacks, it was felt that blended learning might potentially encourage non-attendance at lectures and concerns that online work may not match the standards of offline. In addition, blended learning was viewed as demanding in terms of the time and effort needed to produce and manage online teaching resources. It was also seen to potentially create information overload and crucially reliant upon technology. Finally, perceptions of blended learning surfaced to influence future technology choices when interviewees described their plans for new pedagogical developments. 
The majority of academics in our survey are in the 'traditionalist' group $(n=18)$. Members of this group are not opposed to technology in the classroom, but believe that it must not be allowed to dominate. For the traditionalist, blended learning is defined broadly and may, or may not, include the use of technology, as illustrated below;

I mean, my blended learning does not necessarily have to do with ICT, but I do use a variety of techniques in a sense that it's partly group discussion, partly lecture, partly it's individual work, so it is blended although the blend is not necessarily based on ICT.(ML P4).

It emerged that traditionalists incorporate use of technology at some point in their instruction. Electronic handsets for in-class voting, or answering in-class quizzes, were mentioned as popular with students, although some logistical problems were noted and they were deemed successful only if all students had access to a handset. For the traditionalist, face-to-face, classroom-based teaching remains at the heart of higher education:

I always try to be excited about the subject and don't look bored. There are reasons why I ensure they see me doing it (programming) in class and not to show them just the finished product ... I am honest with students, so they can see the mistakes (I make) ... I tell students that they should use me as a resource, contact me anytime, encourage to ask questions. Students don't use you enough, I think. (TR 4).

The second largest group in our survey is 'pedagogy-centric' $(\mathrm{n}=11)$, clearly delineated by the view that teaching and learning methods and tools must be aligned with course/module aims and objectives:

We don't always know about the impact of certain types of work, so going onto Wimba, or telling students to go onto Facebook and things like that, just because they're the latest things ... If there is not a good pedagogical reason, why should you be doing it? (BLC1).

All academics in this cluster use online tools in their teaching and learning activities, including PowerPoint presentations (in class and online), and provide teaching materials, for example slides, case studies, journal articles, newspaper articles electronically in advance of lectures with the objective of ensuring that students have the opportunity to undertake preparatory reading. All sought to engage students in a dialogue, with the majority using the online learning platform to engender discussions; for the most part these are asynchronous (the lecturer posts a discussion topic, monitors and contributes to the discussion as it progresses). Synchronous discussions were deemed by this group to work most effectively offline; a small number of lecturers in this group intimated that whilst it was straightforward to schedule online chats, in practice participation could be problematical and a small number 
of students could easily dominate the discussion. For the pedagogy-centred academic, the priorities are enhancing learning and ensuring that students achieve stated learning objectives.

We find those in the 'techno-centric' cluster $(n=6)$, populated by those who like to 'stay ahead of the curve'. As well as keeping up to date with the latest technology, the techno-centric instructor favours the use of electronic gadgets in the classroom for their own sake, regardless of whether they play an influential role in enhancing pedagogy. As one interviewee observes:

There are no limitations to blended learning. None! Because you have to use your imagination to adapt blended learning methods to the material you are trying to teach. (BLL1).

It is of interest that in their enthusing about the role of technology in teaching and learning, this group focused upon process and delivery rather than outcome. Personal interest was seen to play a definitive influence in the scope and variety of technology mediated modes of teaching employed by certain instructors.

Blended learning is not just relying on slides, it is important because students get bored in a lecture, so we need to distract them and keep their attention with different methods, especially with new technology. (MLS12).

Keeping abreast of emerging technologies appears to be the key driver alongside the conviction that the effectiveness of their instruction is determined solely by keeping students interested through new gadgets and interactive material. Lecturers in this cluster were innovators in the early days of blogs, podcasts, social networking and mobile technologies, and expressed interest in integrating new tools as they come along;

I am going to radically change and rationalise it [the module]. They [students] won't be motivated to do the self test because they will not have multiple choice questions as a part of their assessment. I will use e-voting system as a means of testing their knowledge. (ML S13).

In contrast, those in the 'cautious' cluster $(n=5)$ are somewhat reluctant to use much technology in teaching. Although they had ventured out and piloted new techniques, they have settled, by and large, for using just a small number of tried and tested teaching and learning tools. This cluster of instructors reported having tried new techniques, for example, online tests in class, only to jettison them. Some explained their retreat from technology in terms of additional stress and students' disappointment when the technology proves unreliable. Others had found it 'clunky' and counter-intuitive, or simply not worth the effort: 
I mean, I think the whole point of lecturer is that it's a person. And even if you use PowerPoint too much then that becomes a barrier and it becomes automatic; if you just leave a tape and let it run and the slides will go through ... If you push blended learning to its ultimate degree, you see well there is no need for a lecturer; you have just got a programme around an administrator who just releases it all at the right time-(TR8).

In relation to our first research objective, we find that academics hold a wide variety of views on blended learning. Although it may have become mainstream in universities, and a central part of teaching and learning strategies in departments of business and management studies, lecturers' enthusiasm is by no means universal. We find the majority in our survey group to be traditionalists who tend to think of blended learning in terms of web-based technology, not averse to employing various methods where they prove fit for purpose, but certainly not enthusiasts. Pedagogy remains at the heart of the teaching and learning strategies, methods and tools employed by the academics in our study.

\subsection{Research objective 2 - Pedagogical aims and instructional design}

Our second research objective was to expose the nature of instructors' pedagogical aims in exploiting blended learning in management education. As we observed earlier, extant research is generally more concerned with technology supported learning as an institutional strategy, in our view failing to delineate adequately between pure online and blended learning environments.

Of central importance to our interviewees' use of blended learning was their understanding of where blended learning fits in pedagogy and their knowledge of the variety of teaching and learning tools available. There were discernable differences between groups. The traditionalists, on the whole, conceptualised blended learning as something to do with new technology, and had limited cognizance of how they were currently exploiting the various learning tools in their instructional design. Many traditionalists were found to be employing blended learning without being fully aware of it:

ML5:'I don't think. I don't think I use anything innovative!' Interviewer:' How about guest speakers, field trips, special case studies, media material?' ML5: 'I do use ... yeah, I do use ... obviously as part of the tutorial stuff, there's lots of case materials. I use one video on that course which generally goes down quite well. Otherwise it's pretty traditional in the approach.

I think I would look at Blended Learning more in terms of support for learning ... . you know, face-to-face learning, rather than as a replacement for it.' 
In contrast, the pedagogy-centric cluster consciously employed blended learning to vary the teaching and learning experience so as to maintain students' interest and to maximise students' understanding:

I try to go beyond transmission which is hard. I try to challenge students by raising questions. I give the students the material that tells them what something does or is but my role as a lecturer is to make them understand why something is structured in a specific way. (P-S4).

The following interviewee expresses a wish to 'break things up' to avoid boredom, maintain attentiveness and encourage participation:

I think it's about different media, breaking up ... you know, everyone knows I think that the attention span is 20 minutes is it or something? It's about refreshing the pace of what's going on. (ML1).

This cluster of respondents concurred that the reasons behind instructional design is driven by pedagogy, as summarised by the following respondent:

It's not just a question of putting up the slides from the face-to-face and hoping that that's useful for somebody. (BLC1).

For the techno-centric group, blended learning leans heavily in the direction of electronic media. This cluster uses electronic stylo-boards in preference to traditional surfaces, kindle, iPads, electronic handsets, videos, podcasts and online social networking tools instead of traditional communication. Academics in this group seek to keep classes active and engaged, based on the premise that engagement and active participation equals learning. At the same time, we observed that interviewees in this group were more alert and enthusiastic than others when discussing the electronic media employed in their blended teaching and learning; as such, there is little doubt that, regardless of institutional strategy, interest and personal preferences play a significant role in academics' embrace of electronic teaching methods, as illustrated by the following;

I use a lot of interactive material for labs. Delivery is structured as follows: Face-to-face lecture - one hour per week, Plus one hour labs which are composed of exercises. Technology used is PPVote, electronic tablet, mobile telephones to enhance participation. Six online discussion forums on the Blackboard.[..] In an ideal world I would have more technology like pod casting, multimedia and interactive materials.[..] I would automate exam assessment on Blackboard, but exam conditions logistics is problematic. (BLL1). 
Unsurprisingly, perhaps, the cautious cluster displayed little interest in the instructional design of blended learning. Conceptualising it primarily as the use of web-based learning platforms, academics in this group were overwhelmingly reactive, as illustrated in the quote:

They say 'Well we have got to use this system, students are starting to expect it, so we'll just load up our PowerPoint slides' and that's blended learning.(MLP13).

The cautious instructor adopts technology in the classroom because of institutional expectations, rather than enthusiasm for blended learning or as a means of ensuring that learning outcomes are achieved.

The findings of the study are summarised in Table 1 . We observe clear distinctions between the clusters in terms of their understanding of the role of blended learning, and their use of various teaching and learning tools. It is interesting to note that a variety of teaching and learning tools are used to support any particular pedagogical strategy. For example, the traditionalists guide students through a case study based group discussion using flipcharts or post it notes, whilst the techno-centric instructor uses online synchronous discussion forums, podcasts and multi-media for the same teaching and learning activity; for the techno-centric cluster, the motivation was specifically to engage students, grab their attention, increase their interest and make teaching sessions more interactive. It is of interest too that, amongst our sample, it was primarily those teaching undergraduate courses that exploit electronic media, specifically for the benefit of interactivity and keeping students interested and engaged with the teaching material as key to effective instruction.

\section{Concluding remarks}

As observed by Oblinger (2006), Gribbens et al. (2007), Bentley et al., (2012) and Turner (2015), the reality of teaching and learning at contemporary universities involves a blend of the online and offline instruction and resources. Arbraugh et al. (2010) called for stronger delineation between pure online and blended learning, and it is clear from our survey that blended learning is at the core of contemporary teaching and learning, with academics exploiting both the physical and virtual worlds as part of their teaching and learning activities.

Based on the challenges of extant studies addressing the characteristics of effective instruction (Bentley et al., 2012; Hwang \& Arbaugh, 2006), we find that the academics in our sample have clear views on how blended learning can be used effectively. To start with, it must be exploited to facilitate the achievement of pedagogical objectives and incorporate 
both offline and online modes. Generally, the majority hold traditionalist views in that they view themselves as the source of subject knowledge and expertise and the locus of knowledge transmission. They tend to favour traditional approaches, based upon face-to-face dialogue, but are willing to supplement to a greater or lesser extent using technological tools that stimulate and enhance dialogic interaction with and amongst students. Offline and online methods are clearly delineated in terms of purpose, although some use various offline techniques somewhat subconsciously. The majority are wedded to traditional teaching and learning methods, heavily focused upon pedagogy. Maintenance of academic integrity; enhancement of the learning experience; ensuring that learning objectives are achieved; and fitness for purpose of the method-in-use are key priorities.

We find that all the academics in our survey use blended learning, even those who view it unfavourably. There are two minority clusters of similar size with relatively entrenched, broadly opposing views, however the majority_agree-that blended learning facilitates student learning and is of value to the extent that it supports teaching and learning aims and objectives. In terms of instructional design we find a variety of blended learning tools in use; in face-to-face encounters didactic methods are still favoured, although there is a considerable amount of dialogic interaction in seminars, tutorials and so on. In addition, numerous electronic tools have found their way into the blended learning environment, including; kindles, electronic voting, online discussion forums, videos, podcasts and social networking tools, and are perceived as useful components of instructional design. The findings also identify a (reasonably large) techno-centric minority who, to varying degrees, experiment with new technology in the classroom in order to maintain students' interest and enthusiasm_(Benson \& Morgan, 2014). The more interactive, electronically-enabled tools tend to be use more extensively for undergraduate than postgraduate teaching and learning. In this regard, we also find a number of frustrated instructors who feel squeezed between the 'top-down' demands of their institution and 'bottom-up' expectations of undergraduate students regarding the use of web-based technologies.

The results of the study indicate that academics make spontaneous dispositional attributions when selecting teaching methods and tools. When confronted with a choice of methods to teach a particular aspect of a module, or course, the traditionalist reaches for the blackboard, whiteboard or flip-board; the pedagogy-centric academic will consider how best to integrate didactic and dialogic, bi- and multi-lateral interactivity, on- and offline methods. The techno-centric instructor favours podcasting, blogging, electronic voting tools and interactive, synchronous online discussions, whilst the extremist sticks to what (s)he has 
always done. One of the key benefits of blended learning is that it allows for structured communications through a formal - informal spectrum of teaching and learning, optimising the chances that, regardless of learning style, individuals will find something that suits them in the varied palette of contemporary teaching and learning tools.

\section{Limitations}

Generalisations of the results of this study are limited in some ways. First, participants in the research were not questioned directly about their motivations for agreeing to take part. Secondly, although the sample was selected to be large enough to maximise the variations in academics' teaching approaches, encompass experiences of both undergraduate and postgraduate programmes, include strategic views of decision makers in teaching and learning development, it may be argued that the sample was not selected to make the results generalizable across all institutions delivering blended business and management programmes. Instead, the findings can be deemed reliable in a number of business education settings and amongst a large number of higher education faculty. Nonetheless, we offer the findings as indicative of some of the issues that need further consideration as universities develop new teaching and learning strategies and methods in the information age.

\section{References}

Åkerlind G., Variation and commonality in phenomenographic research methods, Higher Education Research \& Development 24 (4), 2005, 321-334.

Alavi M. and Gallup R.B., Using information technology in learning; case studies in business and management education programmes, Academy of Management Learning and Education 2 (2), 2003, $139-53$.

Alavi M., Marakas G.M. and Yoo Y., A comparative study of distributed learning environments on learning outcomes, Information Systems Research 13 (4), 2002, 404-415.

Amundsen C., Weston C. and McAlpine G.M., Concept mapping to support university academics' analysis of course content, Studies in Higher Education 33 (6), 2008, 633-652.

Arbaugh J.B. and Benbunan-Fich R., An investigation of epistemological and social dimensions of teaching in online learning environments, Academy of Management Learning \& Education 5, 2006, 435-447.

Arbaugh J.B., Desai A.B., Rau B.L. and Sridhar B.S., A review of research on online and blended learning in the management discipline: 1994-2009, Organization Management Journal 7 (1), 2010, 39-55. 
Arbaugh J.B. and Hwang A., Does "teaching presence" exist in online MBA courses?, The Internet and Higher Education 9 (1), 2006, 9-21.

Baugher D., Varanelli A. and Weisbord E., Student hits in an internet- supported course: how can instructors use them and what do they mean? decision sciences, Journal of Innovative Education 1 (2), 2003, 159 - 79.

Becher T. and Trowler P., Academic tribes and territories, second ed., 2001, Open University Press; Buckingham.

Benson, V. and Anderson, D, Towards a strategic approach to the introduction of blended learning: Challenges faced and lessons learned. British Journal of Educational Technology, 2010, $\underline{41(6), 129-131 .}$

\section{Benson, V. and Morgan, S. (eds.) Cutting Edge Technologies and Social Media Use in Higher}

\section{Education. Hershey, PA: IGI Global, p. 357.}

Bentley Y., Selassie H. and Parkin E., Evaluation of a global blended learning MBA programme, The International Journal of Management Education 10 (2), 2012, 75-87.

Berger K.A. and Tapol M.T., Technology to enhance learning: user of a web site platform in traditional classes and distance learning, Marketing Education Review 11 (3), 2007, 15-26.

Bonk C.J. and Graham C.R., The handbook of blended learning: Global perspectives, local designs, 2006, Pfeiffer; San Francisco, CA.

Brady M., Multiple roles of student and instructor in university teaching and learning processes, The International Journal of Management Education. 11 (2013), 2013, 93-106.

Chen C.C. and Jones K.T., Blended learning vs. traditional classroom settings: assessing effectiveness and student perceptions in an MBA accounting course, Journal of Educators Online 4 (no. 1), 2007, 1-15.

Clark I.F. and James P.R., Using concept maps to plan introductory structural geology course, Journal of Geoscience Education 5 (no. 3), 2004, 224-230.

Clouse S.F. and Evans G.E., Graduate business students performance with synchronous and asynchronous interaction e-Learning methods, decision sciences, Journal of Innovative Education 1 (no. 2), 2003, 181-202.

Entwistle N., Introduction: phenomenography in higher education, Higher Education Research \& Development 16, 1997, 125-126. 
Garrison D.R., Anderson T. and Archer W., Critical inquiry in a text-based environment: computer conferencing in higher education, The Internet and Higher Education 2, 2000, 87-105.

Garrison D.R. and Kanuka H., Blended learning: uncovering its transformative potential in higher education, The Internet and Higher Education 7 (no. 2), 2004, 95-105.

Graham C.R., Realizing the transformational potential of blended learning: comparing cases of transforming blends and enhancing blends in higher education, Blended Learning: Research Perspectives 2007, 83-110.

Gribbens M., Hadidi R., Urbaczewski A. and Vician C., Technology-enhanced learning in blended learning environments: a report, Communications of the Association for Information Systems 20, 2007, 741-759.

Haig B.D., Exploratory factory analysis, theory generation, and scientific method, Multivariate Behavioural Research 40 (no. 3), 2005, 303-329.

Haytko D., Traditional versus hybrid course delivery systems: a case study of undergraduate marketing planning courses, Marketing Education Review 11 (no. 3), 2001, 27-39.

Hwang A. and Arbaugh J.B., Virtual and traditional feedback-seeking behaviours: underlying competitive attitudes and consequent grade performance, Decision Sciences Journal of Innovative Education 4 (no 1), 2006, 1-28.

Ice P., Curtis R., Phillips P. and Wells J., Using asynchronous audio feedback to enhance teaching presence and student sense of community, Journal of Asynchronous Learning Networks 11 (no. 2), 2007, 3-25.

Jones O. and Kerr M., Refreshment by the case: use of multimedia in case study assessment, The International Journal of Management Education 10 (3), 2012, 186-200.

Jones K.R., Moeeni F. and Ruby P., Comparing web-based content delivery and instructor-led learning in a telecommunications course, Journal of Information Systems Education 16 (no. 3), 2005, $265-71$.

Kleinman J. and Entin E.B., Comparison of in-class and distance-learning students' performance and attitudes in an introductory computer science course, The Journal of Computing in Small Colleges 17 (no. 6), 2002, $206-19$.

Klein H.J., Noe R.A. and Wang C., Motivation to learn and course outcomes: the impact of delivery mode, learning goal orientation, and perceived barriers and enablers, Personnel Psychology 59, 2006, 665-702. 
Kupczynski L., Ice P., Wiesenmayer R. and McCluskey F., Student perceptions of the relationship between indicators of teaching presence and Success in online courses, Journal of Interactive Online Learning 9 (no. 1), 2010, 23-43.

Kvale S., Interviews: An introduction to qualitative research interviewing., 1996, Sage; Thousand Oaks, CA.

Lehtinen E., Hakkarainen K., Lipponen L., Rahikainen M. and Muukkonen H., Computer supported collaborative learning: a review of research and development. CL-Net project, The J. H. G. I. Giesbers Reports on Education (number 10)1999, Department of Educa-tional Sciences, University of Nijmegen, Available at:

http://utu.academia.edu/KaiHakkarainen/Papers/314520/Lehtinen_E._Hakkarainen_K._Lippo nen_L._Rahikainen_M._and_Muukkonen_H._1999_._Computer-

Supported_Collaborative_Learning_A_review.

MacDonald D.B. and McNabb D.E., Developing a blended model for MBA content delivery: using internet capabilities to enhance graduate education, In: Proceedings of the 2006 Academic Business World International Conference,in Nashville, Tennessee, 2006.

Marton F. and Booth S., Learning and awareness, 1997, Lawerence Erlbaum Associates; New Jersey.

McMahon J., Gardner J., Gray C. and Mulhern G., Barriers to student computer usage: staff and student perceptions, Journal of Computer Assisted Learning 15 (no. 4), 2001, 302 - 11.

Navarro P. and Shoemaker J., Performance and perceptions of distance learners in cyberspace, American Journal of Distance Education 14 (no 2), 2000, 15-35.

Oblinger D.G., (Ed), Learning spaces, educause, 2006, e-book available from: http://www.educause.edu/learningspaces, Accessed July 18.07.11.

Osguthorpe R.T. and Graham C.R., Blended learning environments: definitions and directions, The Quarterly Review of Distance Education 4 (no. 3), 2003, 227-233.

Rollag A., Teaching with case studies online, Journal of Management Education 34 (no. 4), 2008, 498-526.

Rungtusanatham M., Ellram L. and Siferd S., Toward a typology of business education in the internet age, decision sciences, Journal of Innovative Education 2 (no 2), 2004, 101 - 20. 
Salisbury W.D., Pearson R.A., Miller D.W. and Marett L.K., The limits of information: a cautionary tale about one course delivery experience in the distance education environment, e-Service Journal 1 (no. 2), 2002, 65-81.

Serwatka J.A., Internet distance learning: how do I put my course on the web?, T. H. E. Journal (Technological Horizons in Education) 26 (no. 10), 1999, 71-74.

Stecyk A. and Chojnowski M., Implementation of blended learning project University of Szczecin, Journal of Internet Banking and Commerce 15 (no. 3), 2010, 1-9.

Terry N., Assessing instruction modes for Master of business (MBA) courses, Journal of Education for Business 2007, 220-225, March/April.

Terry N., Owens J. and Macy A., Student and faculty assessment of the virtual MBA: a case study, Journal of Business Education 1 (no. 2), 2000, 33-38.

Thornton K. and Yoong P., The role of the blended action learning facilitator: an enabler of learning and a trusted inquisitor, Action Learning: Research and Practice 8 (no. 2), 2011, 129 $-46$.

Tsai C.-W., The effects of feedback in the implementation of web-mediated self-regulated learning, cyberpsychology, Behaviour and Social Networking 13 (no. 2), 2010, 153-158.

Tsichritzis D., Reengineering the university, Communications of the ACM 42 (no. 6), 1999, 93 100.

Turner Y., Last orders for the lecture theatre? Exploring blended learning approaches and accessibility for full-time international students, The International Journal of Management Education. 2015, [Available online 16 May 2015].

Vician C. and Brown S.A., Reengineering participation through on-line learning environments: an examination of communication apprehension, choice, and performance, Journal of Computer Information Systems 42, 2001, 26-36.

Williams M. and Williams J., Evaluating a model of business school students' acceptance of webbased course management systems, The International Journal of Management Education 8 (3), 2010, 59-70.

Zabriskie F.H. and McNabb D.E., Enhancing the Master of Business Administration (MBA) managerial accounting course, Journal of Education for Business 2007, 226-233, March/April. 
Ziegenfuss D.H., A phenomenographic analysis of course design in the academy, Journal of Ethnographic \& Qualitative Research 2, 2007, 70-79. 